\title{
Rates of Penetration of Fixing Fluids
}

\author{
WILFRID TAYLOR DEMPSTER \\ Department of Anatomy, The University of Michigan, \\ Ann Arbor, Michigan
}

Measurements of the rate of penetration of fixing fluids obviously provide an empirical basis for the minimum timing of tissue fixation, and pioneer studies to this end have appeared in a European literature: Tellyesniczky ('10, '26), Underhill ('32), Medawar ('41), Baker ('58). In addition, however, experimental studies on fixing fluid penetration contribute information on how the fluids act and how cell appearances are changed by preservation.

Tellyesniczky first showed that the components of a fixing mixture separate during penetration and that reagents penetrate tissue in sequence and at characteristic rates. A partially penetrated tissue shows a peripheral stratification with visibly different layers at varying depths from the surface. Measurements of slices cut at intervals from a chunk of tissue submerged in a fixing fluid provide data relating to the rate of penetration of the chemicals.

The implication is clear, though it has not been stated unequivocally in the literature, that a cell at any locus within a tissue in a fixing mixture is provided with a succession of chemical environments. The various constituents of such a cell may be changed physically or chemically, or they may be inert to the first reagent that penetrates. The second reagent may react physically or chemically with the reaction products of the first reagent; it may react with previously unaffected constituents, or, again, it too may be inert. The same reaction possibilities are open to chemicals that penetrate later. The term reaction implies any type of physicochemical action: chemical combinations, responses to $\mathrm{pH}$, denaturing, colloidal differences induced by cations, etc. It is unquestionably clear from the literature that each of these features may have an influence on the bulk, structure and appearance of cellular or tissue elements (Young, '35; Lassek, '50a and '51; Crawford and Barer, '51; Casselman, '55a; Freeman, Moyer and Lassek, '55; Bahr, Bloom and Johannisson, '58; Barrnett and Roth, '58; Hubendick and Blix, '57). One might expect, however, that a different catenation of physicochemical reaction might occur if the several reagents acted in some other sequence. This idea is no contradiction of the chemist's ideas on mass action; it merely suggests that the dropping of a tissue into a three-ingredient fixing mixture is really a complicated three-phase process in which the initial morphological and physicochemical state is potentially changed by the cumulative effects of primary, secondary and tertiary reactions.

The probability is indeed small that a succession of chemical reactions, due to preservative chemicals penetrating in sequence, would kill or fix a cell and leave it exactly isomorphous and isometric with its living state. There is, however, a common idea, of obscure origin, that fixing mixtures are balanced media in which the swelling influence of one reagent is balanced by the shrinkage effects of another. This is obviously only a crude statement of the fact that mixtures - even mixtures containing inert ingredients - often produce less distortion, as seen with the microscope, than the ingredients of the mixture when used separately (Baker, '58). The notion of truly balanced media is contradicted by studies on fixed cells and by measurements of tissue volumes as modified by fixing fluids (King, '10; Tarkhan, '31; Ross, '53; Wüstenfeld, '55; Bloom and Friberg, '56; Bahr, Bloom and Friberg, '57).

The functions of this communication are fourfold: (1) to provide data which will extend, substantiate or correct state- 
ments in the literature on penetration, (2) to consider and evaluate factors that influence penetration rate, (3) to elaborate a concept of sequence of action of fixing reagents, and (4) to propose a practical classification of fixing fluids based on penetration characteristics.

\section{PROCEDURE}

A variety of fresh animal tissue was used in this survey. Tissue from rabbits was most extensively used; over a hundred adult rabbits were killed by concussion and the tissues were excised without delay. Most of the measurements were made on tissues with a relatively homogeneous texture such as liver, muscle (quadriceps femoris), kidney, heart ventricle and brain, but these were supplemented by observations of such heterogeneous tissues as chick embryo, skin, stomach and intestine. Chunks of tissue, preferably 1 to 2 $\mathrm{cm}$ thick were immersed in a volume of fixing fluid at least 25 times the volume of the tissues; to avoid tissue contact with the bottom of the immersion bottle, a bit of glass wool was used as a substrate layer. At various recorded intervals, from 10 minutes to some hours after initial tissue immersion, slices of the tissue were cut from the same end of a tissue chunk and the depth of penetration was measured on the cut surface (to the nearest tenth millimeter), perpendicular to the periphery of the section. Confirmatory measurements were made on at least one other similar tissue for each vessel of reagent; tissues from different animals were routinely used for these repetitions. Unless otherwise indicated, the measured penetration related to room temperature $\left(21-25^{\circ} \mathrm{C}\right)$.

Penetration measurements were made predominantly on 9 standard simple reagents as follows:

$5 \%$ acetic acid

$5 \%$ trichloracetic acid [c]

$10 \%$ formalin (i.e., $4 \%$ formaldehyde)

alcohol (40-100\% at $10 \%$ gradations)

7.5\% mercuric chloride (saturated) [c]

$1.2 \%$ picric acid (saturated) [c]

$2.5 \%$ potassium bichromate

$0.7 \%$ chromic acid [c]

$0.4 \%$ osmium tetroxide

It may be noted that 5 of the reagents [c] fall into Baker's ('58) coagulent class and that the remaining 4 are non-coagu- lents. In addition, experiments were made with a variety of reagent concentrations. Fixing mixtures containing these reagents were prepared from standard formulae (McClung, '29; Lee, '37; Gray, '54). The hydrogen ion concentration and the oxidation potential (Lassek, '50b; Casselman, ' $55 \mathrm{~b}$ ) of many of these fluids are now also on record.

The depth of penetration of simple reagents, as Tellyesniczky pointed out, can generally be determined without the aid of chemical tests, since distinct color changes or differences in tissue consistency are induced in the penetrated regions. When pigmented tissues, such as liver, are placed in fixing reagents (or in water or saline solutions ), the unfixed part of a tissue shows more or less fading of color due to the absorption of water from the medium. This fading or bleaching proceeds to the same degree throughout the tissue and suggests a point-to-point mechanism of water distribution with essentially the same tonicity throughout the tissue. The fading of color in a tissue proved an encumbering factor when uncolored penetrants were studied. At times the delimiting of an uncolored advancing front of a reagent was difficult unless special techniques were devised. Clear cut boundaries between penetrated and unpenetrated tissue, however, were found with most of the reagents. Exceptions were potassium bichromate, which has a diffuse advancing front, and acetic acid and formalin, where bleached-out, unpenetrated tissue and the penetrated layer may not be clearly differentiated. Even with these reagents, however, judgments as to penetration depth showed as great a consistency from hour to hour as data involving more distinct boundaries.

The protein substrate of tissues renders ordinarily sensitive color tests for reagents of little value. Two exceptions, however, were hydrogen peroxide for detecting chromic acid and potassium bichromate, and a dilute alcoholic solution of diphenylcarbazide (preferably alkaline) for coloring tissues penetrated by mercuric chloride. Though the tests were rarely required when simple fixing reagents were employed, they were helpful in determining the extent of penetration when several re- 
agents in a mixture penetrated simultaneously. When two or more reagents which produced a white precipitate or a clouding of tissue were in a mixture, a drop of acid on the exposed section, a drop of alkali, of strong alcohol, of a clearing agent, or of an indicator dye would bring out some degree of distinction in surface color or texture. In several instances where gross measurements were uncertain, frozen sections were made of partially penetrated blocks of tissue and the extent of penetration was checked with the microscope on sections mounted in mineral oil.

\section{RESULTS}

\section{Simple fixing reagents}

When a homogeneous tissue, not permeated by clefts or blood vessels of appreciable size, was immersed in a fixing fluid, the fluid penetrated from the periphery toward the center of the tissue. Rabbit liver was the easiest tissue to measure. When the average depth of penetration into fresh rabbit liver was plotted, the curves shown in figure 1 were produced. As fixing fluids advanced further and further into tissue, the speed of penetration became slower and slower. Each reagent penetrated at a characteristic rate; acetic acid penetrated most rapidly and the relative penetration (for the standard concentrations used) invariably followed the sequence: acetic acid (most rapid), trichloracetic acid, mercuric chloride, picric acid (or) potassium bichromate, chromic acid, and osmium tetroxide (least rapid).

Though Tellyesniczky's data on penetration, as recorded in histograms, referred to different material (autopsy liver, kidney, spleen and brain) and to meager samples of these, to fluids often different in concentration and to fewer, i.e., 4, determinations of penetration depth, one could recognize a rough correspondence between the two groups of data when Tellyesniczky's data were replotted in the form of figure 1. The rate of penetration as now determined was slightly less rapid. Tellyesniczky, however, and Underhill also, failed to recognize that the amount of penetration was not a rectilinear function of the period of immersion.

By plotting the penetration rate logarithmically (i.e., log-log) as in figure 2, the curves become straight lines. The relationships shown in the curves are conveniently described by an empirical exponential formula of the type:

$$
\mathbf{T}=\mathbf{k D}^{\mathbf{e}}
$$

in which $\mathrm{T}$ is the period of immersion, $\mathrm{D}$, the depth of penetration, $\mathrm{k}$, a coefficient relating to the diffusibility of the reagent and $e$, an exponent relating to the rate of diffusion.

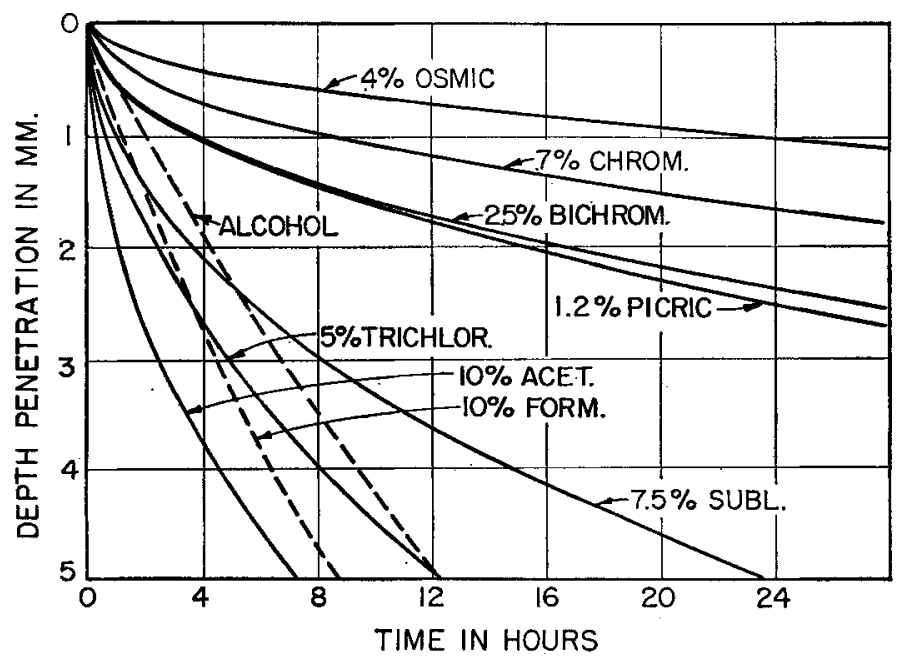

Fig. 1 Plot of depth of penetration relative to time of simple fixing reagents into rabbit liver. 
The average values of the coefficient and exponent are shown in table 1.

For the first 7 curves (numbers 1-7 regular type penetration - fig. 2), the exponent was not far from the square (i.e., exponent 2) of the depth. Thus, the minimum time in hours for complete penetration may be approximated by squaring the requisite depth in millimeters (i.e., half the maximum tissue thickness) and multiplying this factor by the value of the constant "k." The numerical value of the factor " $k$ " was simply the number of hours required for the penetration of the first millimeter of tissue. It ranged from 15 minutes for acetic acid to about 24 hours for osmic acid and, according to the rapidity of penetration, the other reagents fell between these extremes. For practical purposes, the " $k$ " factor implies both the relative speed of penetrants and the sequence of penetration when the ingredients of a mixture have the concentrations of the standards.
The formalin and alcohol curves (figs. 1, 2 and 3; cf. exponent of table 1) showed that the time of penetration was more nearly proportional to the depth of penetration than to the square of the depth. Thus, formalin and alcohol penetrated more efficiently into large chunks of tissue than the regular series of penetrators for which an unusually long time would be required to reach appreciable depths from the surface.

In table 1, the early and late phases of penetration of alcohol were given different constants. The higher concentrations of ethyl alcohol (above $60 \%$ ) acted as tissue dehydrators. (Conversely, alcohols in the $50 \%-10 \%$ range induced increasing degrees of tissue swelling.) On liver, the dehydrating action of the higher concentrations of alcohol extended to a depth of about a millimeter. At this depth, the advancing front of the layer of penetrating alcohol became diluted to such a concentration that the dehydrating action was

TABLE 1

Numerical values pertaining to the factor and exponent of the penetration. formula

\begin{tabular}{|c|c|c|c|c|}
\hline & Fixing reagent & & $\mathbf{k}$ & $\mathbf{e}$ \\
\hline $\begin{array}{l}(1) \\
(2) \\
(3) \\
(4) \\
(5) \\
(6) \\
(7) \\
(8) \\
(9)\end{array}$ & $\begin{array}{l}0.4 \% \text { osmium tetroxide } \\
0.7 \% \text { chromic acid } \\
2.5 \% \text { potassium bichromate } \\
1.2 \% \text { picric acid } \\
7.5 \% \text { mercuric chloride } \\
5.0 \% \text { trichloracetic acid } \\
10.0 \% \text { acetic acid } \\
10.0 \% \text { formalin } \\
95.0 \% \text { alcohol }\end{array}$ & $\begin{array}{r}\text { (initial) } \\
\text { (later) }\end{array}$ & \begin{tabular}{r|}
23.9 \\
8.4 \\
3.94 \\
3.90 \\
0.79 \\
0.67 \\
0.25 \\
1.14 \\
2.00 \\
2.00
\end{tabular} & $\begin{array}{l}1.94 \\
1.99 \\
2.12 \\
2.03 \\
2.09 \\
1.78 \\
2.11 \\
1.25 \\
3+ \\
1.14\end{array}$ \\
\hline
\end{tabular}

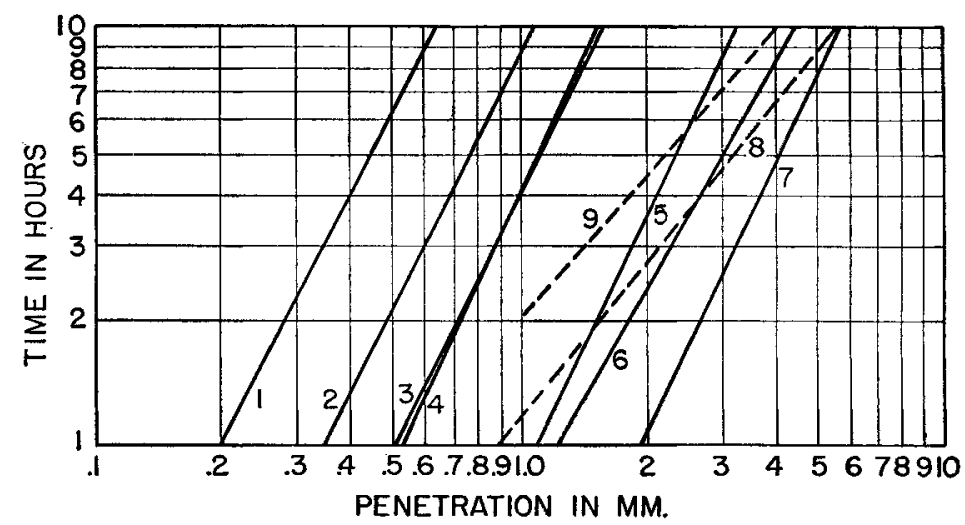

Fig. 2 Log-log plot of depth of penetration relative to time of fixing reagents into rabbit liver. The reagents are: $1,0.4 \%$ osmic acid; $2,0.7 \%$ chromic acid; $3,2.5 \%$ potassium bichromate; $4,1.2 \%$ picric acid; $5,7.5 \%$ mercuric chloride; $6,5 \%$ trichloracetic acid; $7,10 \%$ acetic acid; $8,95 \%$ ethyl alcohol; $9,10 \%$ formal. 
lost. Thereafter the advancing front of alcohol moved at a characteristic rate into the depths of the tissue and coagulated as it advanced. This coagulating concentration of alcohol was probably about $60 \%$ since (when liver was immersed in this grade) no dehydration, i.e., decrease in volume, occurred; in addition, the coagulum produced looked the same at both the surface and the interior. The initial dehydrating phase affecting the first millimeter of penetration was more rapid for higher alcohol concentrations than for those of 80 or $70 \%$. Where one wants a pure dehydrating action without coagulation from alcohol, tissues should be less than two millimeters thick. Supporting evidence that the "active" grade of alcohol is of intermediate concentration is suggested by: (1) studies by bacteriologists (Buchanan and Fulmer, '30) which indicated that $60-70 \%$ alcohols have the greatest germicidal value and by (2) experiments (Mann, '02) using alcohol which showed quantitatively that $50 \pm 10$ $\%$ alcohol caused a high degree precipitating action on histological material.

Although $10 \%$ formalin diffused into tissue at a rate roughly comparable with that of the second phase of alcohol penetration, the problem was different. Increased concentrations to $20 \%, 30 \%$ or $100 \%$ were noticeably more rapid. Curves with the higher grades of formalin had the same slope as curves representing the $10 \%$ formalin but the " $\mathrm{k}$ " factor was lower.

Analytical experiments (Medawar, '41) have shown that fixing reagents penetrated into tubes of coagulated blood serum (or gelatin/albumin and gelatin/nucleoprotein gels - Baker, '58) in accord with the laws of diffusion. The depth of penetration my be plotted as linearly proportional to the square root of the time of penetration (viz., $1 \mathrm{hr} .=1^{2}$ hrs.; $4 \mathrm{hrs}$. $=2^{2}$ hrs.; $9 \mathrm{hrs} .=3^{2} \mathrm{hrs}$.; $16 \mathrm{hrs} .=4^{2}$ hrs., etc.); figure 3 shows the present data on liver plotted in this way. The data of curves 1-7 (fig. 2 and table 1) for which the exponent " $e$ " was close to 2 readily produced consistent curves; moreover, the data showed approximately the same sequence of penetration as the gels where equivalent reagents and concentrations

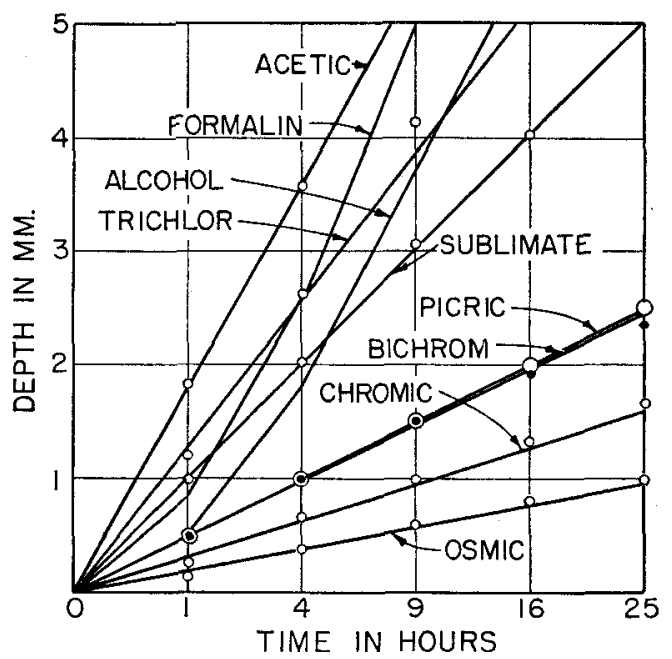

Fig. 3 Depth of penetration of fixing reagents into rabbit liver plotted relative to the square root of the time.

could be compared. Since, however, the time rate of penetration into tissues was roughly half that into homogeneous gels, the latter data are not a sure practical guide as to the time required for penetration. (Furthermore, the gel data indicate the same rate obtains for days and weeks; because of autolytic changes in tissues, however, one should not expect that penetration for more than a few hours would have value.)

We cannot think of normal physiological mechanisms (ion exchange, phosphorylation, etc., Osterhout, '33) when penetration into tissues involving cell death and protein precipitation are involved. The special "physiology" of fluid shifts at the advancing front of a penetrating killing and fixing medium can scarcely be adumbrated. Certainly there are fluid movements both into and out of the tissue and one may expect complex pressure gradients, too. Two observations relating to tissue pressures and to the nature of the interface between penetrated and unpenetrated tissue require comment.

First, after a cube of liver or other homogeneous tissue with plane sides had been immersed in a coagulent fixative, the sides were initially flat as a peripheral "skin" of penetrated tissue formed. Then, with increasing time, the central part of each face began to bulge under the pres- 
sure of the unpenetrated tissues deep to the penetrated layer. The edges of the cube, however, were from the start more resistant. When the thickness and toughness of the "skin" increased enough, the bulging reached a limit. Similarly, when successive slices were cut from the same end of an immersed tissue, the face most recently cut always compensated for the increasing tissue pressure by bulging notably. As a precipitating concentration of the coagulent solute left the solution to unite with tissue constituents, it released solvent water which diffused away, and an appreciable quantity of this water obviously moved into the unpenetrated tissue. The uniform bleaching out of color and the uniform texture of unpenetrated liver tissue suggest that excess water is rapidly distributed through the tissue. Although the same phenomenon no doubt occurred to a degree with non-coagulents, the penetrated layer was softer and yielded readily.

Secondly, it was found that frozen sections of a partially penetrated tissue mounted in mineral oil gave a good view of the advancing front of a coagulent reagent. For instance, frozen sections (i.e., cross sections) through a partially penetrated muscle where a colored coagulent fluid (viz., picric acid) was used showed that the advancing front of the reagent was more intimately associated with tissue elements than with the intercellular fluid. The yellow-colored fluid appeared to be attracted to the surfaces of the muscle fibers and from here it penetrated into the depth of the fiber; the inter-cellular spaces were scarcely tinted. Further toward the surface where the cells and fibers were thoroughly permeated, the tint of the reagent appeared clearly in the spaces between the fibers. Liver and testis showed a comparable movement of picric acid through the formed tissue elements rather than a uniform advance through both the cells and intercellular spaces. Penetration which advances against a pressure gradient in a step-wise fashion from the intercellular spaces to cell surface to cell interior certainly shows an appreciably slower rate than penetration into homogeneous protein gels.

\section{Modifying factors}

Similar tissues from different animals. Livers from a variety of freshly killed animals were penetrated at approximately the same rate as rabbit liver. The variation in rate from sample to sample was comparable also. The material included guinea pigs, rats, sheep, alligators, bull frogs and slaughter house hogs. (Tissue from the hogs could not be immersed till about three-quarters of an hour after the tissue had been removed from the animals.)

Different tissues. When homogeneous bulky tissues (as testes, muscle, heart, kidney, brain and liver) were immersed in the several simple fixing reagents, the differences in the order of penetration into the different tissues were small and not uniformly consistent. The penetration into testes and muscle was usually more rapid than into brain and liver. Even pig skin (dermis and epidermis) and pig costal cartilage showed quite usual rates of penetration. The capsule of the liver, spleen or kidney offered no special resistance to penetration, but the tunic of the sheep testes did delay penetration slightly. In each instance, the time of penetration of reagents, other than alcohol and formalin, into each tissue was approximately proportional to the square of the depth, i.e., differences appeared in the " $k$ " factor of the formula rather than in the exponent.

Capillarity. Most striking differences in penetration rate appeared in the rabbit renal medulla or in muscle where penetration perpendicular to the axes of the renal tubules or of the muscle fibers was obviously more rapid. This difference in rate, due to capillary or surface wetting action, showed, when the data were plotted, as a flatter slope of the logarithmic curves (i.e., exponent of less than 2). At a right angle to the axes of tubules of the medulla or muscle fibers (or in the cortex of the kidney), the slant of the curves was normal.

Surface-volume relationships. When fixing fluids were injected intravascularly a large surface was provided for entrance of the penetrating chemicals. Whether or not a fixing fluid was injected after blood had been flushed from blood vessels by saline or Ringer's fluid, and whether a head of pressure similar to normal blood pressure or a much higher pressure was maintained, 
complete and immediate penetration was never really obtained. Ordinarily a third to a half of the cut surface of an injected liver was coagulated in a mottled pattern surrounding blood vessels. Injection merely provided a large surface, the vascular bed, through which fixing fluids could penetrate into adjacent tissue. Commonly, however, the smaller vessels were constricted and plugged by the action of a fixing fluid and the potential vascular surface was limited. When the kidneys were immediately removed from several rabbits after the intravascular injection of fixing fluids, much of the cortex was seen to be coagulated, but in no instance was the medulla appreciably involved. (It will be remembered that medullar arterioles typically receive blood after it flows through glomeruli within the cortex). The distribution of coagulated tissue may be explained by the plugging of small vessels in the cortex before they reach the medulla. Sequential penetration from vascular channels was easily observed when fixing mixtures containing two or three slowly penetrating reagents were injected into a homogeneous tissue such as liver. Penetration sequence was shown by concentric perivascular layers of coagulated tissue. Even smears of cells and cellular suspensions may be presumed to be penetrated by fixing reagents acting in sequence.

When the surface of a piece of tissue is great in relation to volume, for instance, if relatively large blood vessels permeate a tissue or if clefts increase the ratio of surface to volume, the tissue bulk will be penetrated more rapidly. Embryonic tissue, for example, presents special avenues for fixing fluid entrance along clefts surrounding the eye and central nervous system, along the lining of the neural tube and along serous surfaces. As far as could be discerned from 8 day chick embryos and such slowly penetrating reagents as osmic and chromic acids, penetration into the more compact embryonic regions, such as liver, brain or the tissues of the rump region, was roughly similar to that found with homogeneous adult tissues. Penetration, however, could not be measured for longer than an hour or so because of the small size of the organs. The same mode of penetration was shown by a small frog immersed in mercuric chloride. Fixation was accelerated through channels of fluid entrance similar to those found in embryos. Likewise, chunks of non-homogeneous adult tissues, the walls of the gastrointestinal tract, for example, provide extensive surfaces between layers and within crypts which allow more rapid penetration than in a homogenous tissue.

Conversely, if tissue rests on the bottom of a container or floats so that the upper surface is partly exposed, penetration is impeded on the lower or upper surface as the case may be.

Tissue swelling and shrinkage. Various authors (King, '10; Tarkhan, '31; Wüstenfeld, '55; Bloom and Friberg, '56) have measured the volumes of tissues before and at intervals after immersion into simple fixing reagents or fixing mixtures; some made repeat measurements for many days after the initial immersion. None, however, have distinguished between volume changes during the penetration process and volume changes following complete permeation. From the published data one may generally assume that after the first day or two, when complete penetration may be expected, (1) volumes continue to decrease for weeks, but at a decreasing rate with time, and (2) when a tissue shows initial swelling, its later shrinkage in a fixing fluid may be less than for tissues in other fluids which initially showed less or no swelling. It is significant to note that when authors measure volumes and ignore the extent of reagent penetration, their data on the early stages of the fixation process are singularly incomplete. The penetrated peripheral layer of a partly penetrated tissue may be swollen or shrunken or unchanged in volume and its actual status may be masked by the degree of swelling of the yet unfixed tissue.

I have observed that liver and other adult tissues, when immersed in water, Ringer's fluid or in aqueous fixing fluids, absorb water readily (Parry, '36; Wolf, '40). The swelling often amounted to a bulk increase of from 25 to $50 \%$. Whether in water, Ringer's fluid or the aqueous fluids, tissue, some hours after excision, swelled more readily than fresh tissue. Such swollen tissue had a notably less com- 
pact character than fresh tissue or fresh soaked tissue.

Chunks of sheep liver were assorted into 4 groups. In the control group, fixative penetration and measurements began immediately after the death of the animal. The remaining pieces were set aside for 30 hours (at room temperature) prior to immersion in the fixing reagents: (1) in a moist chamber, (2) in distilled water, and (3) in Ringer's fluid. Measurements of fixing fluid penetration showed definitely more rapid penetration of the 30 hour moist chamber material than of fresh liver for each of 4 reagents used (acetic acid, sublimate, picric acid and chromic acid); the tissue swelled much more noticeably than fresh tissue during penetration. Autolytic changes caused both increased water absorption and increased fixing fluid penetration. This difference in rate may account for the more rapid penetration shown in Tellyesniczky's data. The wet tissues (much swollen in contrast to the moist chamber material) were still more rapidly penetrated by all the reagents, though the difference was slight for chromic acid. Water immersed tissue in most instances was more rapidly penetrated than that immersed in Ringer's. Again, it was in the " $k$ " factor rather than in the exponent that the curves differed.

What seems particularly significant is that for each tissue studied, whether fresh or old, acetic acid penetrated most rapidly; osmic acid was slow and the relative penetration invariably followed the sequence shown in figures 1,2 and 3.
Reagent concentration. The concentrations of the standard reagents used in the present investigation were comparable to those used in many common fixing mixtures. For contrast, three reagents were prepared in various concentrations as follows: trichloracetic acid - $20 \%, 10 \%$, (5\%) $, 2.5 \%, 1.25 \%, 0.63 \%, 0.32 \%$ and $0.16 \%$; mercuric chloride- $(7.5 \%), 3.75 \%$, $1.82 \%, 0.93 \%, 0.47 \%$ and $0.23 \%$; chromic acid-11.2\%, $5.6 \%, 2.8 \%, 1.4 \%$, $(0.7 \%), 0.35 \%, 0.17 \%$ and $0.086 \%$. The standard concentrations are included in parentheses. For each reagent, log-log curves of penetration into liver roughly paralleled one another, and in every instance they had the same sequence as the order of dilution. (Figure 4 shows as many grades of concentration as could be plotted without confusion; the preparation of smoothed average curves as those of figure 2 were not warranted by the limited data.) The concentrated fluids consistently penetrated more rapidly than less concentrated ones. The " $\mathrm{k}$ " factor varied with concentration, but the exponent remained unchanged.

When a tissue was placed in a very small amount of fixing reagent of ordinary concentration, the reagent penetrated initially at a normal rate, then, in subsequent time intervals as the fluid surrounding the tissue became less concentrated due to absorption by the tissue, the slope of the log-log curve deviated to the left and eventually became vertical at a point when no further penetration occurred. In effect, the slope changed and the exponent " 2 "

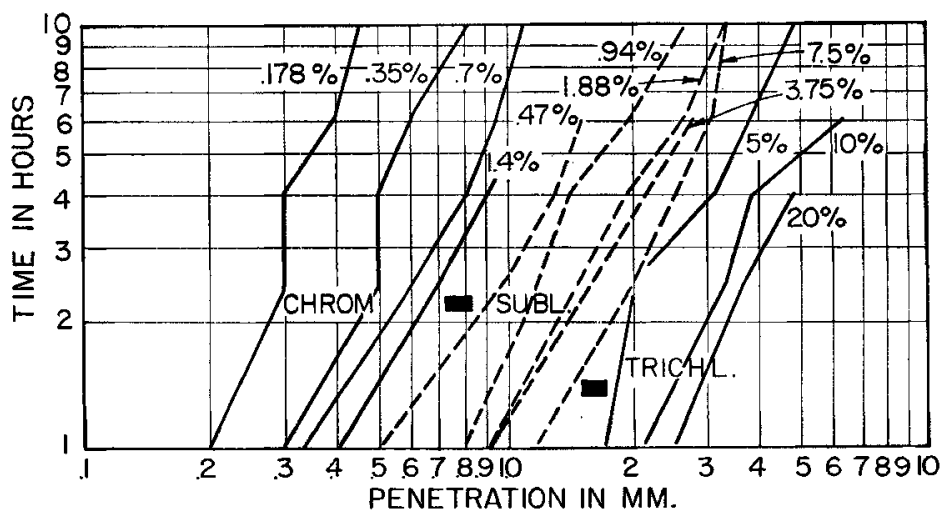

Fig. 4 Log-log plot of penetration of several concentrations of three simple fixing reagents into rabbit liver. 
changed through a series of ascending values to infinity. In practical tissue fixation, this effect may be obviated through the use of adequate quantities of fixing fluid or by re-immersion in fresh fluid.

Osmotic effects. It is a common assumption, since Mann ('02), that osmotic phenomena are active during the penetration of fixing fluids. Stoltzner ('06), using the freezing point depression method, determined the osmotic pressures of fixing reagents. Several standard fixing formulae contain sodium chloride or other inert salts so that the reagents are dissolved in a fluid supposedly isotonic with blood. Sugars, sea water salts and other osmotic agents have also been combined with certain fixing reagents (Hirsch and Jacobs, '26; Schiller, '30; Young, '35; Bahr, Bloom and Johannisson, '58).

Saline fluids that are isotonic for the erythrocyte are not necessarily isotonic for other tissues and especially for tissues that have been excised. Tissue removed from an animal and deprived of its blood supply -often brought to a much lower temperature than its normal physiological range and injured mechanically - apparently does not have the same property of tonicity as when in the intact animal (Hooker and Fischer, '12; Parry, '36). It tends to swell in "isotonic" media.

Colloidal swelling of immersed tissue was reduced or eliminated in high concentrations of inert fluids. After an hour or two in $16 \%$ sucrose solution (or in $4 \times$ normal Ringer's fluid), the volume of chunks of rabbit liver (1 cm thick) remained at a relatively constant volume (90-95\% of original volume) for a period of at least 20 hours. Figure 5 shows the rate of penetration into such tissue by $.7 \%$ chromic acid (A), $1.2 \%$ picric acid (B) and $7.5 \%$ mercuric chloride (C) made up in ( $16 \%$ ) sugary media; the reduced rates of penetration (dashed lines) may be compared with those of the standard reagents lacking the adulterants and acting on freshly excised rabbit liver (solid lines). As indicated by the arrows in the graph, the addition of sugar in each instance resulted in a decreased rate of penetration. This slower rate may be contrasted with the fluid soaked and swollen sheep liver referred to previously in which penetration rates were significantly increased. Where tissue volume was increased by marked colloidal swelling and the tissue was less compact, penetration was rapid; where swelling was prevented, the penetration rate was decreased. Again only the constant " $k$ " in the formula was affected and the relative penetration order of reagents of standard concentration was unaltered.

It might be expected that each of the ingredients of a fixing mixture might increase the osmotic pressure of the fluid so that the speed of penetration of the separate components would be slowed in comparison to their normal rate of penetration as simple reagents. Measurements of penetration rate, however, have shown no clear

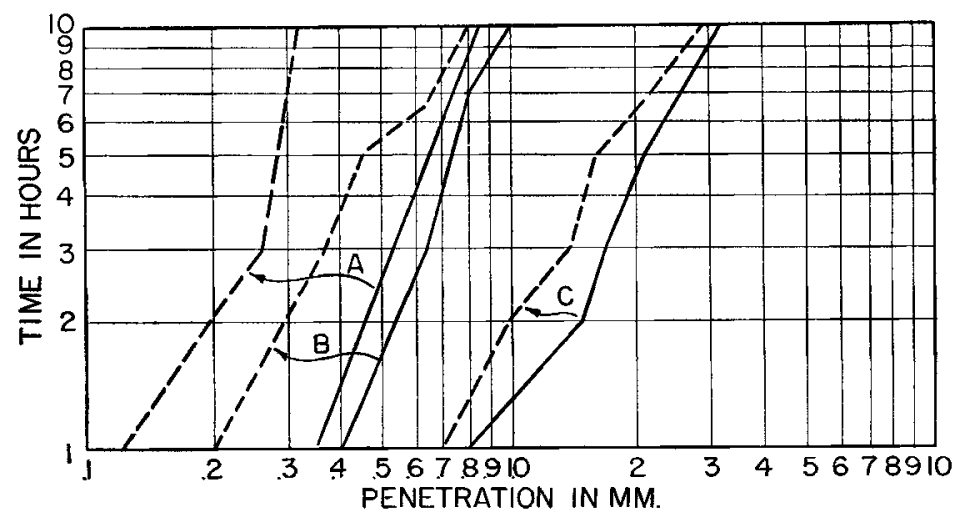

Fig. 5 Log-log plot of penetration of fixing reagents (A, $0.7 \%$ chromic acid; B, $1.2 \%$ picric acid; $\mathrm{C}, 7.5 \%$ mercuric chloride) into rabbit liver. The solid lines refer to aqueous solutions of fixing reagents; the dashed lines relate to fixing reagents made up in $16 \%$ sucrose solutions. 
evidence of this modifying factor. If it exists, its effects must be negligible.

Thermal effects. Samples of rabbit liver were subjected to picric acid, chromic acid and mercuric chloride in a cold room (temp. $9^{\circ} \mathrm{C}$ ), in an incubator room $\left(38.5^{\circ} \mathrm{C}\right)$ and at a room temperature of $28^{\circ} \mathrm{C}$. Figure 6 shows individual curves of material in chromic acid and sublimate. These curves and data from picric acid material as well (which could not be plotted clearly on the same graph) show that penetration at $9^{\circ}$ was as much slower than at $28^{\circ}\left(19^{\circ} \mathrm{C}\right.$ difference) as penetration at $38.5^{\circ}$ was faster $\left(10.5^{\circ} \mathrm{C}\right.$ difference). Though increasing temperature noticeably increased penetration rate, augmented autolytic changes would more than neutralize the possible advantage of an increased rate.

\section{Sequential penetration}

Pig liver which had been thoroughly permeated with $10 \%$ formalin was subsequently immersed in such simple reagents as $5 \%$ acetic acid, 95\% alcohol, 5\% trichloracetic acid or saturated mercuric chloride. There was little difference in absolute rates when penetration into fixed tissue was compared with penetration into unfixed tissue. If tissues were first permeated by acetic acid or were pre-soaked in $60 \%$ alcohol, they were more readily permeated than normal by mercuric chloride and picric and osmic acids. The slightly more rapid penetration into acetic acidsoaked tissue may be accounted for by the swollen texture of the tissue that resulted from the action of acetic acid. It would appear that either rapid or slow penetrants may be used as second order fixing fluids if miscible combinations of reagents are selected.

\section{Fixing mixtures}

Tellyesniczky ('26), in the revision of his 1910 paper, pointed out that the fixing reagents in a fixing mixture do not enter tissues en masse, but that each reagent penetrates tissue in a characteristic sequence. This principle has been definitely substantiated in the present study. A specific illustration will serve to show the mode of penetration of fixing reagents in a mixture. Figure 7 represents rabbit liver penetrated by Zenker fluid $(4.7 \%$ acetic acid, $4.7 \%$ sublimate and $2.3 \%$ bichromate); each ingredient penetrated the tissue at a characteristic rate, acetic acid first, then sublimate and finally bichromate. If these curves are compared with the equivalent curves of figure 1, it will be seen that differences are small, especially when the slightly different concentration of reagents is considered.

Measurements similar to those on Zenker fluid have been repeated for a number of standard mixtures with equivalent results but no exhaustive survey of fixing fluids has been made. Variations in concentration of reagents from one mixture to another appear to be the only features which might alter the sequence of penetration of a given group of reagents. The

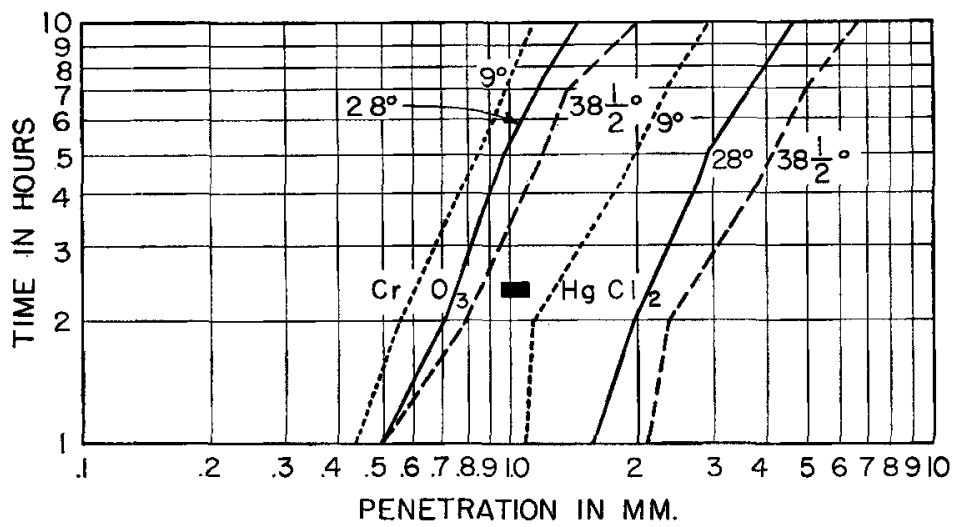

Fig. 6 Log-log plot of the penetration of $0.7 \%$ chromic acid and saturated sublimate into rabbit liver at three temperatures. 


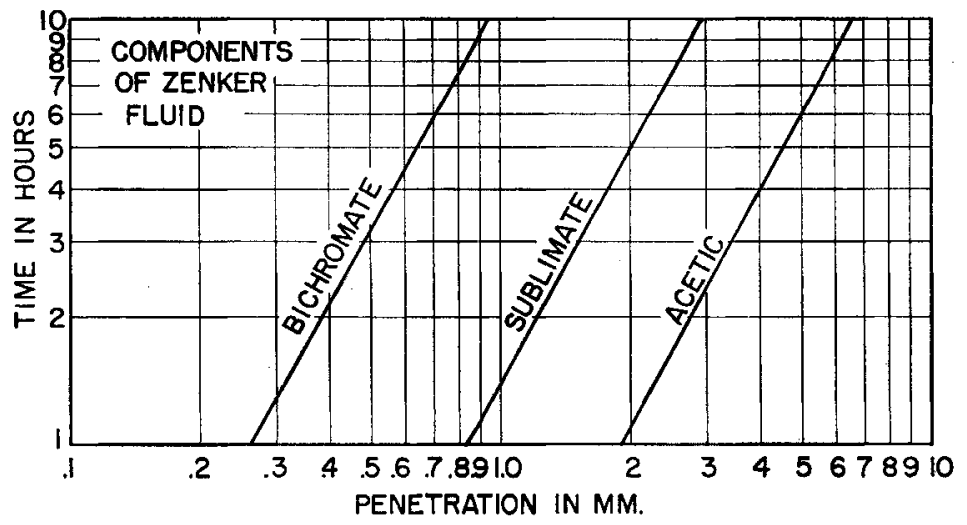

Fig. 7 Log-log plot showing how the constituents of Zenker fluid separate and penetrate rabbit liver in an orderly sequence.

range of concentration of reagents in the standard mixtures, however, is small and one may predict the sequence of penetration with some accuracy. In most cases, it has been easy to check sequence by just two or three successive measurements after a couple of hours penetration into liver. In a few instances, frozen sections or chemical tests have been used.

\section{Fixing fluids classified}

Fixing fluids in works on microtechnique are commonly classified according to certain "dominant" or "characteristic" reagents. Thus, formalin, mercuric chloride or osmium tetroxide have been recognized as key reagents in fixing mixtures. Schemes based on this convention are obvious conveniences for the listing of fixing fluid formulae but they would seem also to imply that the fluids within a group possess similar actions, cause similar cytological appearances, cause similar staining, or give rise to similar degrees of swelling or shrinkage - these assumptions, however, do not appear to be supported by evidence. Usually, microtomists settle on some few favorite media as formalin, or Bouin's or Flemming's fluid or some traditionally accepted formula and the numerous alternates (Gray, '54) are ignored.

A classification based on rate and sequence of penetration (table 2) should have a positive advantage in that it should provide a rational approach toward assessing the similarities and differences in tissue appearances due to fixation, and it should also suggest new ways of combining fixing agents for special uses:

It should be of interest to know for any fixing mixture:

1. the reagents making up the mixture,

2 . the order of penetration of reagents, and

3. the presence of a reagent which may penetrate at a unique exponential rate.

The most rapidly penetrating constituent will impose a primary condition which may be modified in some way by the slower reagents according to the sequence of their reaction. Table 2 permits one to view quickly a wide range of fixing mixtures in terms of both the ingredients and their order of penetration - the names in parentheses are the current eponyms. The abbreviated listing should clearly indicate the ingredients and their sequence of penetration; a degree of euphony should be desirable. The sequence of reaction should be implied in the terminology. Thus, Bouin's fluid should be regarded not as picroformol, but as aceto-formol plus picric (of Bouin). The regular series includes only those reagents that penetrate in sequences at essentially the same exponential rate. These mixtures will fix more or less uniformly from the surface to the interior of a tissue. The irregular series includes formalin and aqueous alcohol which penetrate at different exponential rates from other ingredients of the mixtures. The irregular fixing mixtures, thus, represent a changing sequence of penetration of the 
reagents at different distances from the surface of a tissue.

When stained sections were examined with the microscope, tissues fixed in the "regular" fixing mixtures showed uniform staining characteristics over the whole area of sections; those fixed in the "irregular" mixtures ordinarily showed a peripheral layer of cells (about $1 \mathrm{~mm}$ thick) in which staining was different from that further toward the center of the section. Characteristically, low-power, black-and-white photomicrographs of sections from tissues fixed in "irregular" mixtures showed marked photo-density differences between the peripheral and central regions.

No personal evaluation of mixtures is implied in this presentation; no cytological comparisons of cells fixed with the various mixtures have been made. There is, however, an extensive literature in this area which relates to either basic reagents or specifically named mixtures. (Krishna, '48; Zeiger, '49; Glick, Engstrom and Malm-

TABLE 2

I. Acetic acid group

\section{Regular series of fixing mixtures}

A. Anhydrous Aceto-alcohol (Carnoy; Farmer)

1. Aceto-alcohol and chloroform (Carnoy)

2. Aceto-alcohol and chloroform + sublimate (Ohlmacher, LeBrun, Sanson)

B. Aceto-trichloracetic

1. Aceto-trichloracetic and sublimate (Heidenhain)

C. Aceto-sublimate ("Corrosive acetic")

1. Aceto-sublimate and bichromate (Zenker)

D. Aceto-picric

1. Aceto-picric and osmium (von Rath)

E. Aceto-bichromate (Tellyesniczky)

1. Aceto-bichromate and chromium (Goldsmith)

F. Aceto-chrom

1. Aceto-chrom and osmium (Flemming, Winiwarter, Benda, Meeves)

II. Trichloracetic group

1. Trichloracetic-alcohol and sublimate (Huber)

III. Sublimate group

A. Sublimate-picric (Rabl)

B. Sublimate-osmium (Mann)

IV. Bichromate group

A. Bichromate-chrom

1. Bichromate-chrom and osmium (Champy)

B. Bichromate-osmium (Altmann)

Ia. Acetic acid group

Irregular series of fixing mixtures

A. Aceto-alcohol, aqueous

1. Aceto-alcohol and formalin (Lavdowsky, Kahle, etc.)

2. Aceto-alcohol and formalin + picric (Alcoholic Bouin)

3. Aceto-alcohol and sublimate + nitric (Petrunkevitch)

B. Aceto-formal

1. Aceto-formal and trichloracetic + sublimate ("Susa")

2. Aceto-formal and sublimate (Worcester)

3. Aceto-formal and picric (Bouin, Hollande-Bouin)

4. Aceto-formal and picric + chrom (Allem B-15)

5. Aceto-formal and bichromate (Held)

6. Aceto-formal and chrom ("Chrom-acetic-formal")

IIa. Formalin group

A. Formal-trichloracetic

1. Formal-trichloracetic and sublimate (Romeis)

B. Formal-sublimate (Heidenhain)

1. Formal-sublimate and bichromate (Zenker formal, Helly, Maximow, Bensley)

C. Formal-bichromate (Orth, Regaud)

D. Formal-chrom

1. Formal-chrom and osmium (Kauffmann) 
strom, '51; Haselmann, '51; Palade, '52; Policard, Bessis and Bricka, '52; Porter and Kallman, '53; Baker and Modern, '52; Ross, '53; Federlin and Köster, '54; Siering, '54). Without a basic classification of fluids, however, much of the value of this type of comparison is lost.

Experimental trials with two- or threephase fixation (Wallington, '55; Elftman, ${ }^{5} 57$ ) might be extended far beyond present attempts. For instance, tissues might be permeated first by a single slowly penetrating reagent (by immersion or injection), and this could be followed as a subsequent procedure by immersion in a second simple reagent or in a mixture till permeation is complete. Elftman pointed out that potassium bichromate and osmium tetroxide react optimally at entirely different hydrogen ion concentrations and that sequential penetrations of the two ingredients are more effective than penetration of a mixture which must have an indifferent, non-optimum $\mathrm{pH}$.

In presenting this classification, I do not want to imply that it is more than a start toward a rational organization of fixing fluids. It does not include more than a few of the numerous mixtures that have been proposed (Gray, '54). It may be extended by including new reagents or new combinations of the standard chemicals. Different sequences of penetration involving two or three stages of immersion fixation could extend the classification. Perhaps a suitably augmented classification should include attention also to $\mathrm{pH}$, osmotic pressure and/or other variables. Perhaps even the determination of sequence of penetration should be more rigorously controlled. For instance, a classification such as the present one could be improved if it related to (1) the " $\mathrm{k}$ " factor at one hour of immersion, (2) for a standardized room temperature, and ( 3 ) for a standard tissue of standard size. Perhaps this sketching out of a classification may suggest the need of a still better plan.

\section{SUMMARY}

Fresh vertebrate tissues were immersed in either simple fixing reagents or in fixing mixtures. The depth of penetration at various time intervals was measured on cuts perpendicular to the surface. Although frozen sections and tinctorial reactions were occasionally used, penetrated tissues were routinely identified and measured directly. The ingredients of the mixtures separated out during penetration, and each proceeded at a rate comparable to that of the simple ingredient acting alone. The depth of penetration became slower with each additional interval of time. Straight line log-log plots and exponential formulae adequately described the rate of penetration. Inert isotonic media, colder temperatures and dilution increased penetration times while heat and high concentrations of reagents accelerated penetration. Intravascular fixation provided large surfaces from which reagents permeated into the tissues, but the basic rates from the surfaces were comparable to those of homogeneous tissues. A tissue element at a depth from the surface was exposed in sequence to the action of the components of a fixing mixture. For the typical reagents the sequence of penetration at different depths from the surface was about the same; mixtures with formalin or alcohol, however, showed a graded change at different levels since an initially slow reagent (viz., formalin) may overtake initially faster penetrants. Penetration studies should provide a basis for a rational classification of fixing mixtures.

\section{LITERATURE CITED}

Bahr, G. F., G. Bloom and E. Johannisson 1958 Further studies on fixation with osmium tetroxide. Histochemie, 1: 113-118.

Bahr, G. F., G. Bloom and U. Friberg 1957 Volumenveränderungen von histologischen Präparaten während der Fixierung und Einbettung. Verh. Anat. Gesellsch., 53: 113-121.

Baker, R. F., and F. W. S. Modern 1952 Controlled fixation with osmium tetroxide. Anat. Rec., 114: 181-187.

Baker, J. R. 1958 Principles of Biological Microtechnique; A Study of Fixation and Dyeing. John Wiley \& Sons, Inc., New York.

Barrnett, R. J., and W. D. Roth 1958 Effects of fixation on protein histochemistry. J. Histochem., 6: 406-415.

Bloom, G., and U. Friberg 1956 Shrinkage during fixation and embedding of histological specimens. Acta Morph. Neerl. Scand., 1: 12-20.

Buchanan, R. E., and E. I. Fulmer 1930 Physiology and Biochemistry of Bacteria. Vol. 2, Effects of Environment upon Microörganisms. Williams \& Wilkins Co., Baltimore.

Casselman, W. G. B. 1955a Cytological fixation by chromic acid and dichromates. Quart. J. Micr. Sci., 96: 203-222. 
$1955 \mathrm{~b}$ The relative oxidizing properties of certain reagents and mixtures used for the fixation of tissues. Ibid., 96: 223-226.

Crawford, G. N. C., and R. Barer 1951 The action of formaldehyde on living cells as studied by phase-contrast microscopy. Ibid., 92: 403-452.

Elftman, H. 1957 Osmichrome fixation. Ibid., 98: $15-18$.

Federlin, K., and E. Köster 1954 Der Einfluss verschiedener Fixierungsmittel auf die Kerngrösse. Frankfurt Ztschr. Path., 65: 493-502.

Freeman, B. L., E. K. Moyer and A. M. Lassek 1955 The $p H$ of fixing fluids during fixation of tissues. Anat. Rec., 121: 593-600.

Glick, D., A. Engstrom and B. G. Malmstrom 1951 A critical evaluation of quantitative histo- and cytochemical microscopic techniques. Science, 114: 253-258.

Gray, P. 1954 The Microtomist's Formulary and Guide. Blakiston, New York.

Haselmann, H. 1951 Analyse mikromorphologischer Vorgänge bei der histologischen Fixation mittels Phasenkontrast-Mikrokinematographie. Anat. Anz., 97 (suppl.): 149-152.

Hirsch, G. C., and W. Jacobs 1926 Experimentelle Untersuchungen über das Wesen der Fixierung. I : Úber den Einfluss "isotonischer" (aequimolekularer) und "anistonischer" (inaequimolekularer) Fixierungsflüssigkeiten auf die Fixierung. Ztschr. Zellforsch. Mikr. Anat., 3: $198-228$.

Hooker, M. O., and M. H. Fischer 1912 tuber die Aufnahme von Wasser durch das Nervengewebe. Ztschr. Chemie. Indust. Kolloide, 10: 283-294.

Hubendick, B., and R. Blix 1957 Composition of osmium fixatives with a certain osmotic pressure and a certain pH. Arch. Zool., 10: $459-462$.

King, H. D. 1910 The effects of various fixatives on the brain of the albino rat, with an account of a method of preparing this material for a study of the cells in the cortex. Anat. Rec., 4: 213-244.

Krishna, D. 1948 Shrinkage of animal cells due to fixatives. Nature, 161: 202-203.

Lassek, A. M. 1950a A study of the precipitating effects of basic fixing solutions. Anat. Rec., 107: 409-414.

$1950 \mathrm{~b}$ The hydrogen-ion concentration of the primary fixing solutions. Stain Tech., 25: $43-46$.

- 1951 An experimental study on the general utility of concentrated (commercial) formalin as a fixative. Anat. Rec., 109: 757759.

Lee, A. B. 1937 The Microtomist's Vade-Mecum; A Handbook of the Methods of Microscopic Anatomy, 10th ed. Ed. by J. B. Gatenby and T. S. Painter. P. Blakiston's Son and Co., Inc., Philadelphia.

McClung, C. E. 1929 Handbook of Microscopical Technique for Workers in Both Animal and Plant Tissues. Paul B. Hoeber, New York.

Mann, G. 1902 Physiological Histology; Methods and Theory. Clarendon Press, Oxford.

Medawar, P. B. 1941 The rate of penetration of fixatives. J. Roy. Micr. Soc., 61: 46-57.
Osterhout, W. J. V. 1933 The kinetics of penetration. V. The kinetics of a model as related to the steady state. J. Gen. Physiol., 16: 529557.

Palade, G. E. 1952 A study of fixation for electron microscopy. J. Exp. Med., 95: 285-298.

Parry, A. A. 1936 Initial swelling of excised muscle in fluid media. J. Cell. and Comp. Physiol., 8: 277-287.

Policard, A., M. Bessis and M. Bricka 1952 La fixation des cellules isolées observée au contraste de phase et au microscope électronique. I. Action des différents fixateurs. Bull. Micr. Appl., Ser. 2, 2: 29-42.

Porter, K. R., and F. Kallman 1953 The properties and effects of osmium tetroxide as a tissue fixative with special reference to its use for electron microscopy. Exp. Cell Res., 4: 127-141.

Ross, K. F. A. 1953 Cell shrinkage caused by fixatives and paraffin-wax embedding in ordinary cytological preparations. Quart. J. Micr. Sci., 94: 125-139.

Schiller, W. 1930 Gewebsfixierung unter Exhaltung der basichen Kernfärbung mit einem Anhang über den Bander Leberzelle. Ztschr. Zellforsch., 11: 63-178.

Siering, H. 1954 Schädigung cytologischer Präparate durch verschiedene Fixierungsmittel. Acta Med. Scand., 149: 229-236.

Stoeltzner, H. 1906 Der Einfluss der Fixierung auf das Volumen der Organe. Ztsch. Wiss. Mikr. 23: 14-25.

Tarkhan, A. A. 1931 The effects of fixatives and other reagents on cell-size and tissue-bulk. J. Roy. Micr. Soc., 51: 387-400.

v. Tellyesniczky, K. 1910 Fixation (Theorie und Allgemeines). In: Enzyklopädie der microskopischen Technik, 2nd ed. Ed. by P. Ehrlich, R. Krause, et al. Urban and Schwarzenberg, Berlin, vol. 1, pp. 460-473.

1926 Fixation: Theorie, Allgemeines, Zellenfixation, fixation und Nach-behandlung. In: Ibid., 3rd ed. Urban and Schwarzenberg, Berlin, vol. 2, pp. $750-785$.

Underhill, B. M. L. 1932 The rate of penetration of fixatives. J. Roy. Micr. Soc., 52: 113120.

Wallington, E. A. 1955 Secondary fixation as a routine procedure. J. Med. Lab. Technol., 13: $53-67$.

Wolf, A. V. 1940 Weight changes of hydrated, normal, and dehydrated frog muscles in Ringer's solution. J. Cell. and Comp. Physiol., 15: 355-361.

Wüstenfeld, E. 1955 Experimentelle Beiträge zur Frage der Volumenänderungen und Eindringdauer in der histologischen Technik. I. Der Einfluss von 5 Fixierungsflüssigkeiten auf das Volumen von Leber, Niere, Milz und Muskel bei Zimmertemperatur. Ztschr. Wiss. Mikr., 62: 241-247.

Young, J. Z. 1935 Osmotic pressure of fixing solutions. Nature, 135: 823-824.

Zeiger, K. 1949 Haftpunkttheorie und histologische Fixation. Ztschr. Zellforsch. Mikr. Anat., 34: 230-256. 